Check for updates

Cite this: RSC Adv., 2019, 9, 19606

Received 1st May 2019

Accepted 10th June 2019

DOI: $10.1039 / c 9 r a 03248 g$

rsc.li/rsc-advances

\section{Characteristics of nanoparticle formation and hazardous air pollutants emitted by 3D printer operations: from emission to inhalation $\uparrow$}

\author{
Jong-Sang Youn, ${ }^{\mathrm{a}}$ Jeong-Won Seo, ${ }^{\mathrm{b}}$ Sehyun $\mathrm{Han}^{\mathrm{a}}$ and Ki-Joon Jeon (iD *a
}

\section{Introduction}

The popularity of desktop three dimensional (3D) printers is rapidly increasing. ${ }^{\mathbf{1 , 2}}$ The original purpose of 3D printers was to create prototypes before launching new products. ${ }^{3}$ However, recently the scope of $3 \mathrm{D}$ printers has been expanded to the medical and education fields, and industry. ${ }^{4-6}$ Various $3 \mathrm{D}$ printing methods have been developed, such as fused filament fabrication (FFF), selective laser sintering (SLS), and stereo lithographic apparatus (SLA).$^{1,7}$ Among these methods, the FFF method is most frequently used because it is inexpensive and easy to use. ${ }^{8}$

FFF-type 3D printers use the extrusion of polymer base thermoplastic materials as a filament under high temperature conditions $\left(\sim 200{ }^{\circ} \mathrm{C}\right) .^{8}$ It is well-known that the thermal processing of polymer materials release toxic air pollutants, including carcinogens and chemicals that cause nervous system disorders. ${ }^{9-11}$ The composition of the toxic air pollutants produced during the thermal heating process is very complex because of the many types of thermoplastics. ${ }^{12}$ Furthermore, FFF-type 3D printers are known to emit particulate matter with sizes of $<100 \mathrm{~nm}$ and volatile organic compounds (VOCs)

${ }^{a}$ Department of Environmental Engineering, Inha University, Michuhol-gu, Incheon 22212, Korea.E-mail: kjjeon@inha.ac.kr

${ }^{b}$ Department of Ophthalmology, Hallym University, Dongtan Sacred Heart Hospital 7 , Hwaseong-si, Gyeonggi-do, Republic of Korea

$\dagger$ Electronic supplementary information (ESI) available. See DOI: 10.1039/c9ra03248g because of filament extrusion. ${ }^{13}$ Moreover, this study evaluated nanoparticles and VOCs emissions from 3D printers by type of $3 \mathrm{D}$ printer and filament and used it to evaluate nanoparticle and total VOC emission factors. Particulate matter emission rate of $3 \mathrm{D}$ printers have been studied by work place conditions, ${ }^{14}$ type of 3D printers, ${ }^{13,15}$ and printing parameters. ${ }^{16} \mathrm{Kim}$ et al. (2015) and Vance et al. (2017) measured the aerosol and VOCs emissions from acrylonitrile butadiene styrene (ABS) and polylactic acid (PLA) filaments and showed large difference by types of filaments. ${ }^{17,18}$ While significant attention has been focused on particulate matter and total VOC emissions from 3D printers in previous studies, no study has been investigated nanoparticle formation, emissions of hazardous air pollutants (HAPs), and emissions upon inhalation in the human respiratory tract.

Although most of the particles size larger than $0.1 \mu \mathrm{m}$ effectively collect in the upper respiratory tract because of inertial collision, nanoparticles $\left(D_{\mathrm{p}}<100 \mathrm{~nm}\right)$ penetrate deeper into the lower respiratory tract, infiltrating the extra-thoracic, conducting, and pulmonary systems upon inhalation. ${ }^{19-21}$ These nanoparticles can then pass through the bloodstream and contaminants contained in the nanoparticles can diffuse in bloodstream and can be consumed by macrophages. ${ }^{22}$ Therefore, understanding deposition behavior of nanoparticle emitted from 3D printer is crucial factor in terms of human health perspective. Moreover, HAPs are toxic air pollutants that can cause cancer and other severe reproductive and birth defects. ${ }^{23,24}$ Hence, the US environmental protection agency (EPA) manages 187 species of toxic air pollutants classified as 
HAPs which include some VOCs, polycyclic aromatic hydrocarbons (PAHs), pesticides, and heavy metals. ${ }^{25}$

The goal of this study was to measure the nanoparticles and HAPs produced during 3D printing to obtain the following results: (1) nanoparticle size distribution as a function of time; (2) nanoparticle morphology and elemental composition; (3) nanoparticle deposition behavior in the human airway; and (4) characteristics of HAP emissions.

\section{Materials and methods}

\subsection{FFF-type 3D printers}

Nanoparticle and HAPs emissions from 5 FFF-type 3D printers were measured. Although Yi et al. (2016) reported that the air pollutant emission characteristics vary depending on filament color, so we used common white filaments to minimize the influence of color pigments. ${ }^{26}$ Filaments were extruded and injected from the printer nozzle at $230{ }^{\circ} \mathrm{C}$ onto the sample bed which heated at $80{ }^{\circ} \mathrm{C}$. The detailed operation conditions are summarized in Table 1 . In this system, the nozzle moved on the $X$ and $Y$ axis, and the sample bed was downed from the top or fixed at the bottom as the $Z$ axis. We used commercially available FFF-type 3D printers (FINTBOT Z420, TPC Mechatronics Corp., South Korea). To confirm that nanoparticle formation was enhanced by the increased number of 3D printer operating, we designated five measurement periods over a total of $3 \mathrm{~h}$ sampling time: (1) background (22 $\mathrm{min}),(2)$ a single 3D printer operation (phase 1; $23 \mathrm{~min}$ ), (3) two 3D printer operation (phase 2; $21 \mathrm{~min}$ ), (4) five 3D printer operation (phase 3; $40 \mathrm{~min}$ ), and (5) background (22 min). A 10 min break was taken between second and third phases to confirm that the nanoparticle formation was inhibited.

\subsection{Sampling and analytical methods}

Measurements were performed in a $126 \mathrm{~m}^{3}$ size 3D printing center in Inha University. Room layout and experimental setup is provided in Fig. S1. $\dagger$ With the exception of the office furniture, instruments, and 3D printers, the room was empty during sampling and the ventilation system was turned off to reduce the interruption of background emissions. Real-time particle number size distribution was measured using a scanning mobility particle sizer (SMPS; TSI, USA) at $80 \mathrm{~s}$ scan time. The sampling ports were placed $1 \mathrm{~m}$ from each of the $3 \mathrm{D}$ printers and $1 \mathrm{~m}$ from the office floor. To analyze nanoparticle

Table 1 The 3D printer operating conditions

Printer type

Filament type

Hot-end temperature $\left({ }^{\circ} \mathrm{C}\right)$

Bed temperature $\left({ }^{\circ} \mathrm{C}\right)$

Layer height $(\mathrm{mm})$

Bottom/top thickness

$(\mathrm{mm})$

Fill density (\%)

Filament diameter $(\mathrm{mm})$

Nozzle size $(\mathrm{mm})$ morphology and elemental composition, the samples were characterized by transmission electron microscopy (TEM; JEM2100F, JEOL, Japan) at $200 \mathrm{kV}$ with energy dispersive spectroscopy (EDS). A TEM grid (Ted Pella, Inc., USA) was placed in the mini particle sampler (MPS; Ecomesure Inc, France) connected to a mini pump (MP- $\sum 30$, SIBATA, Japan). TEM grid sampling was conducted in phase 3. Moreover, we analyzed the $3 \mathrm{D}$ printer filaments to confirm the emission source of the nanoparticles. The morphology and elemental composition of the filaments were characterized using a field emission scanning electron microscope (FE-SEM; S-4300SE, Hitachi, Japan) equipped with EDS.

\subsection{Aerosol deposition model}

Aerosol particle deposition modeling for the human respiratory system was conducted using particle dosimetry ${ }^{27-29}$ and pulmonary morphometric models ${ }^{\mathbf{3 0 , 3 1}}$ ranging in complexity. In the simplest human respiratory models, various semi-empirical models can provide accurate results using a small number of parameters. In this study, we used the multiple-path particle dosimetry (MPPD, v3.04) model, ${ }^{32,33}$ which evaluated deposition of $10 \mathrm{~nm}$ to $20 \mu \mathrm{m}$ particles over the entire respiratory system. The MPPD model has been used in diverse research fields including pure inorganic aerosol, bioaerosol, indoor sources, cigarettes, and biomass burning. ${ }^{34-38}$ To calculate the number dose of particle deposition in each airway generation, the deposition rate (DR) during 3D printing operation was calculated by the eqn (1):

$$
\mathrm{DR}\left(\# \mathrm{mim}^{-1}\right)=\mathrm{DF} \times C \times \mathrm{TV} \times \mathrm{BF}
$$

here, DF is deposition fraction, $C$ is particle number concentration $\left(\# \mathrm{~cm}^{-3}\right)$ of the $i$ th SMPS channel obtained from experimental work, TV is tidal volume $\left(\mathrm{cm}^{3}\right)$, and BF is breathing frequency $\left(\mathrm{min}^{-1}\right)$. Then number dose (\#) of each airway generation is calculated using DF value by eqn (2):

$$
\text { Number dose }(\#)=\sum_{t_{\text {stop }}}^{t_{\text {start }}} \mathrm{DR}
$$

The deposition density $\left(\# \mathrm{~cm}^{-2}\right.$ ) was calculated by applying the surface area of each generation provided by the MPPD model. Further details regarding the model input parameters are provided in Tables $\mathrm{S} 1$ and $\mathrm{S} 2 . \dagger$ The human lung geometry used in the MPPD model of this study is anatomically divided into airway generation numbers. ${ }^{39}$ Generation number 1-20 and 21-28 represent the tracheobronchial (TB) region and the acinar (AC) region, respectively.

\subsection{HAPs sampling and analysis}

Gas phase sampling was conducted using a personal mini pump connected to $280 \mathrm{mg}$ of Teneax TA (40/60 mesh, Markers Inc., UK). Sampling was conducted three times for $5 \mathrm{~min}$ each in phase 3 and blank samples were collected in first background stage. The blank sample concentrations were subtracted. The samples were then analyzed by gas chromatography-mass 
spectrometry (GC-MS; HP 6890/5973, Hewlett Packard, USA; DB1 column, $0.32 \mathrm{~mm} \times 60 \mathrm{~m} \times 3 \mu \mathrm{m})$ coupled with a thermal desorption apparatus (TDA). We analyzed total 34 gas species and confirmed that 14 of them were HAPs species.

\section{Results and discussion}

\subsection{Nanoparticle formation}

The nanoparticle number concentration and size distribution were measured using SMPS in the size range from 11 to $350 \mathrm{~nm}$ (Fig. 1). At the beginning of sampling, the size resolved particle number concentrations of the room was measured as a background reading for $20 \mathrm{~min}$, showing a unimodal distribution with a peak at $90 \mathrm{~nm}$. Subsequently, the 3D printers were turned on in order, and a bimodal distribution emerged with peaks at 15 and $90 \mathrm{~nm}$. In phase 1 , the formation of $<20 \mathrm{~nm}$ nanoparticles began to be detected and 70-100 $\mathrm{nm}$ nanoparticles increased only slightly. During phase 2 , the nanoparticle concentration with sizes ranging between 10 and $30 \mathrm{~nm}$ increased. The number concentration of 70-100 $\mathrm{nm}$ particles at the beginning of phase 2 was similar to that observed in phase 1. However, it gradually increased as a function of time because the $10-30 \mathrm{~nm}$ nanoparticles presumably agglomerated and 70$100 \mathrm{~nm}$ large single nanoparticles were also emitted. The nanoparticle characteristics at the beginning of phase 2 were similar to those observed in phase 1 . During the break time in between phase 1 and 2, the $10-30 \mathrm{~nm}$ particle number concentration decreased but that of the 70-100 nm particles remained similar to that measured in phase 2 . Formation of the 70-100 nm particles occurred via agglomeration ${ }^{\mathbf{4 0 , 4 1}}$ of the smaller nanoparticles emitted during phases 1 and 2 . In phase 3 , five $3 \mathrm{D}$ printers were operated simultaneously. During this phase, it was confirmed that the $10-30 \mathrm{~nm}$ particle concentration dramatically increased initially with the highest concentration of all sampling periods. After phase 3, nanoparticle sampling was conducted without $3 \mathrm{D}$ printer operation to obtain an after-background reading. Inhibition of 10-30 $\mathrm{nm}$ particle emissions from 3D printer was confirmed, whereas that of the 70-100 nm particles remained at similar number concentrations during the after-background measurement due to

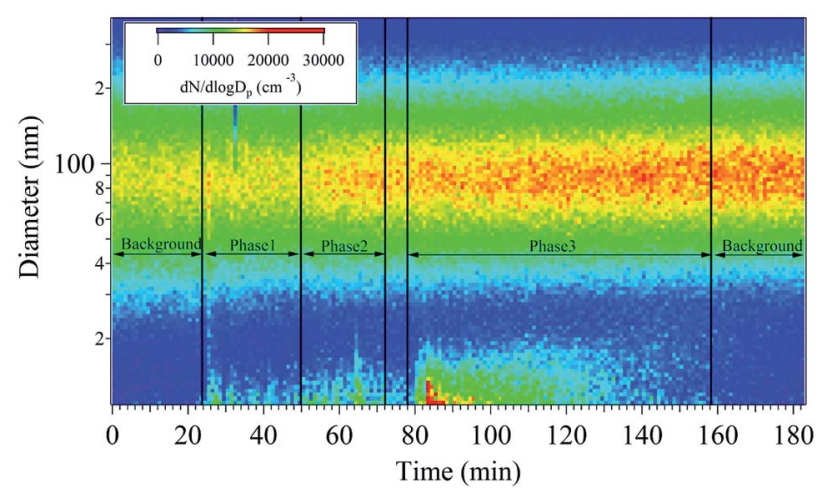

Fig. 1 Real-time measurement of the particle number concentrations as a function of particle diameter and time. nanoparticle agglomeration. This indicates that the emitted particles lingered in the room at size of $70-100 \mathrm{~nm}$, which is most inhalable particle in the human respiratory system. ${ }^{\mathbf{4 2}}$

Fig. 2 shows the average nanoparticle size distributions with phase change. The unimodal distribution with a dominant peak at $88 \mathrm{~nm}$ was observed in the background reading. During phase 1 , the $88 \mathrm{~nm}$ peak did not clearly increase, but the $10 \mathrm{~nm}$ peak appeared because of the nanoparticle formation originating from the 3D printers. During phases 2 and 3, the prominent peak at $10 \mathrm{~nm}$ noticeably increased in intensity and the secondary peak at $88 \mathrm{~nm}$ also increased. This indicates nanoparticle formation from the operation of the 3D printers, confirming that nanoparticle formation was accelerated by the use of an increasing number of 3D printers. With increasing duration, the concentration of the $88 \mathrm{~nm}$ nanoparticles increased, which indicates that the $10 \mathrm{~nm}$ nanoparticles became agglomerated or larger nanoparticles were directly emitted.

\subsection{Nanoparticle morphology and elemental composition}

The morphology and elemental characteristics of the emitted nanoparticles were analyzed using TEM-EDS (Fig. 3). Most of the nanoparticles emitted from 3D printers are agglomerated near-spherical nanoparticles (Fig. 3(a)). In the 50-150 nm range, single spherical nanoparticles were analyzed (Fig. 3(b)). These particles were likely generated when the filament was melted and injected into the 3D printer sampling bed. The majority of the 10-20 $\mathrm{nm}$ nanoparticle emissions from the 3D printers agglomerate to form larger particles approximately $100 \mathrm{~nm}$ in size. Moreover, the direct emission of the approximately $100 \mathrm{~nm}$ sized particles contributed to the increase in the number concentration of the nanoparticle size ranging between 70 and $100 \mathrm{~nm}$. This indicates the emission of gaseous species, which will be further discussed in the last section. The primary particle size is critical, since the deposition fraction and deposited areas in the human respiratory system differ depending on particle size. ${ }^{43}$ The median primary particle size

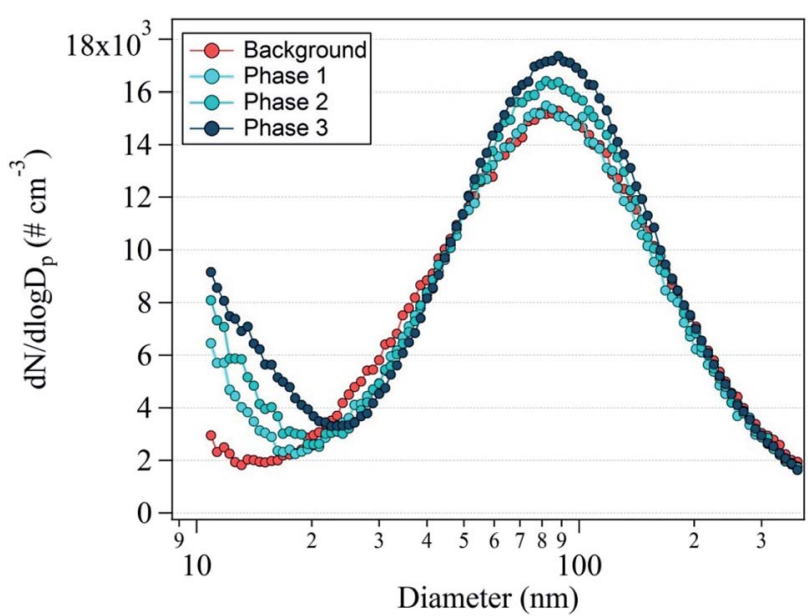

Fig. 2 Average number size distribution of the nanoparticles during the background measurement and phases 1, 2, and 3 . 

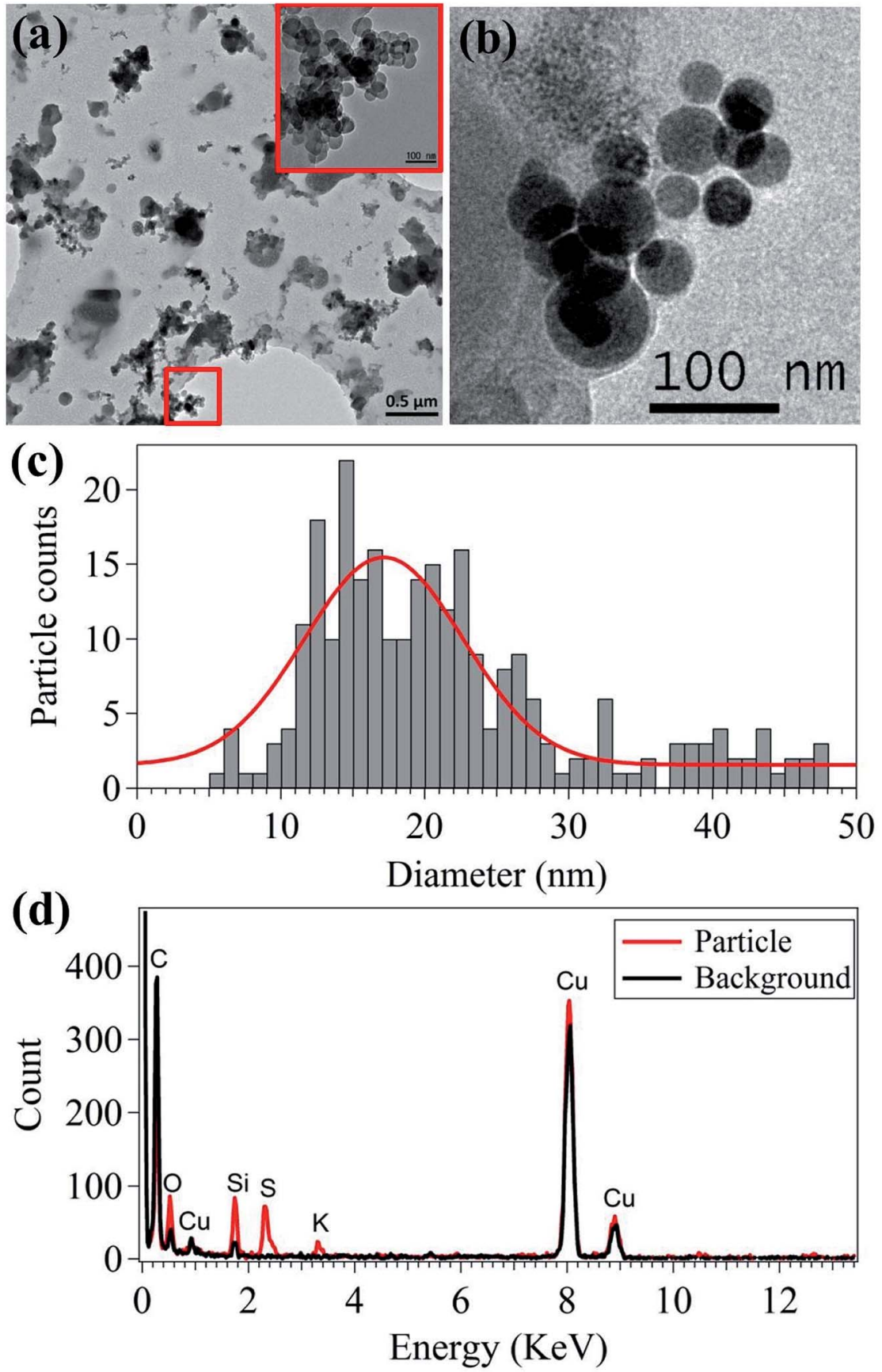

Fig. 3 Nanoparticle morphologies (a and b), primary particle size distribution (c), and elemental composition (d).

was $19.85 \mathrm{~nm}$, as shown in Fig. 3(c), which corresponds to the primary particle size shown in Fig. 1 and 2.

In addition to nanoparticle morphology, the elemental composition of the nanoparticles was analyzed using TEM-EDS (Fig. 3(d)). $\mathrm{C}$ and $\mathrm{Cu}$ were detected in both the particle and background measurements because holey $\mathrm{C}$ coated $\mathrm{Cu}$ grids were used. Si, S, and $\mathrm{K}$ were mainly detected in the primary particles (20-30 nm). Si and $\mathrm{K}$ were expected and originated from the additive material used in the filament manufacturing process. Fig. 4 shows the SEM-EDS results of the filament. Most of the filament surface was smooth, except for some convex protrusions (Fig. 4(a)). The EDS analysis of the filament showed $\mathrm{C}, \mathrm{Si}$, and $\mathrm{Mg}$ on the surface (Fig. 4(b)). The Si in the filament agreed with the TEM-EDS results. Therefore, it was confirmed that $\mathrm{Si}$ and $\mathrm{K}$ originate from the additive materials in the polymer used for filament manufacturing. Moreover, the $\mathrm{S}$ in the nanoparticles was presumably originated from the heating the nozzle material at the high temperature.

\subsection{Nanoparticle deposition model results}

To study the potential health effects of the nanoparticles emitted from $3 \mathrm{D}$ printers, it is important to determine the 


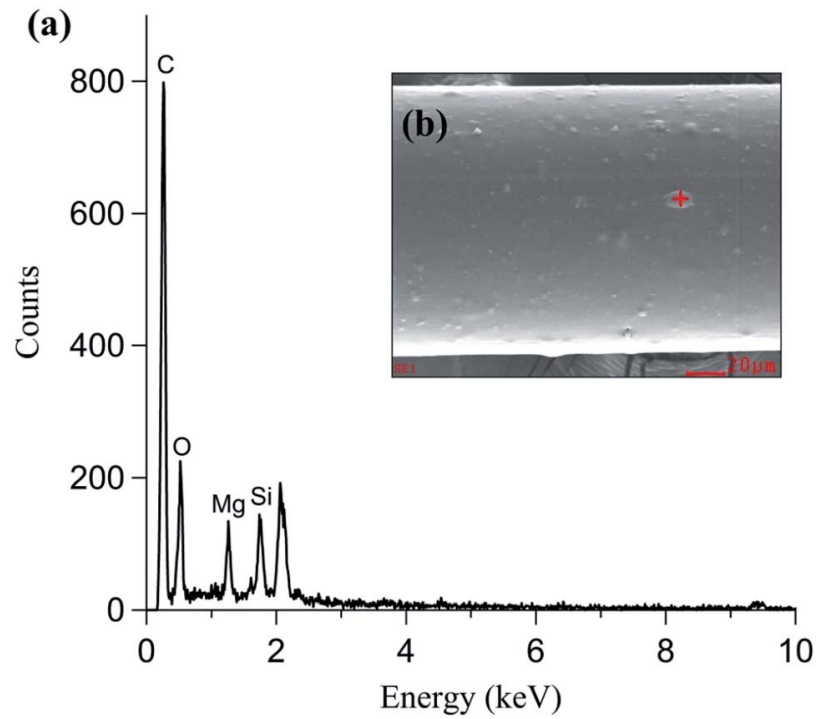

Fig. 4 PLA type filament (a) elemental composition and (b) morphology.

number of nanoparticles that could be deposited in human respiratory tract as a function of airway generation number. The particle dose in the human respiratory system during 3D printing is shown in Fig. 5. In Fig. 5(a), the maximum particle dose occurred at the 20th airway generation with $4 \times 10^{6}$ particles. Moreover, approximately $70 \%$ of the nanoparticles are deposited in the human respiratory system ranging in generation number from 16 to 28 . These results indicate that the nanoparticles deposited in the pulmonary region which consists primarily of alveolar airways. ${ }^{44}$ Fig. 5(b) shows the contour plot of the particle number dose as a function of both particle size and airway generation number. The highest particle number dose $\left(6.6 \times 10^{6}\right)$ was observed at the nanoparticle size of $15.1 \mathrm{~nm}$ and the 19th airway generation. The 10$40 \mathrm{~nm}$ nanoparticles showed the highest particle number dose range, located between the airway generation number 16 and 22. This indicates that a large number of nanoparticles are deposited in the lower respiratory tract compared to that of the upper respiratory tract.

Aerosol particle inhalation research typically considers deposition density and particle number dose per airway generation surface area as important parameters because each generation is characterized by different anatomical surface areas. ${ }^{44}$ Fig. 6 (a) shows the nanoparticle deposition density by airway generation number, showing that maximum deposition density occurred in the third airways $\left(3.7 \times 10^{4} \mathrm{~cm}^{-2}\right)$. Approximately $60 \%$ of the deposition density appeared in the airway number between 1 and 5 , at the starting point of the tracheobronchial region in the upper respiratory tract. This is likely because the surface areas of the airway generation number from 1 to 5 are approximately 2 to 530 times smaller than that of the surface areas of the airway generation ranging from 6 to 28 (Table S2†). ${ }^{33}$ Fig. 6(b) shows the deposition densities according to both nanoparticle diameter and airway (a)
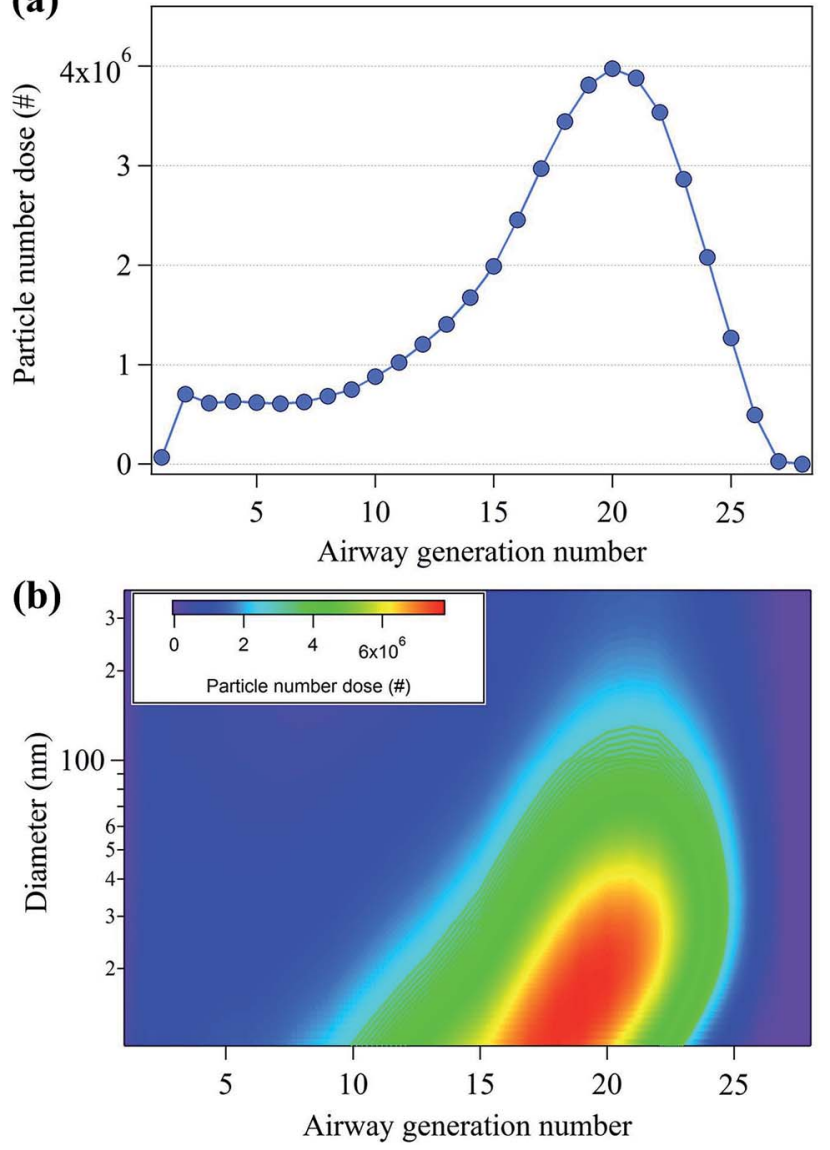

Fig. 5 (a) Total particle number dose (\#) per human air generation number and (b) particle number doses per human airway generation number and nanoparticle diameter.

generation number. The highest deposition densities were observed for particles with diameters between $10-40 \mathrm{~nm}$.

\subsection{HAPs in gaseous emissions}

Previously, it was shown that VOCs were emitted along with nanoparticles from 3D printer operation, and they focused on total VOCs (TVOCs) emissions and associated emission factors. ${ }^{13,17}$ However, understanding the species present in the gaseous emissions in terms of exposure assessment for each gas species is important. ${ }^{45}$ Of the 34 gaseous species analyzed, 14 were considered classified as HAPs, which are known to be carcinogens or cause serious impact on human health and the environment. ${ }^{25}$ The analyzed HAPs are shown in Fig. 7 , and the descriptive concentrations of the 14 HAPs and their associated health effects are summarized in Table S3. $\dagger$ The International Agency for Research on Cancer (IARC) classifies chemicals in terms of groups of suspected carcinogens. ${ }^{46}$ From the HAPs results, benzene and trichlorethylene are designated as group 1 carcinogens which are obviously carcinogenic to humans. The benzene and trichlorethylene concentrations were determined to be 0.52 and $0.09 \mathrm{ppb}$, respectively. Even though these concentrations are low, it has been reported that long-term exposure to these chemicals at low concentrations can cause 

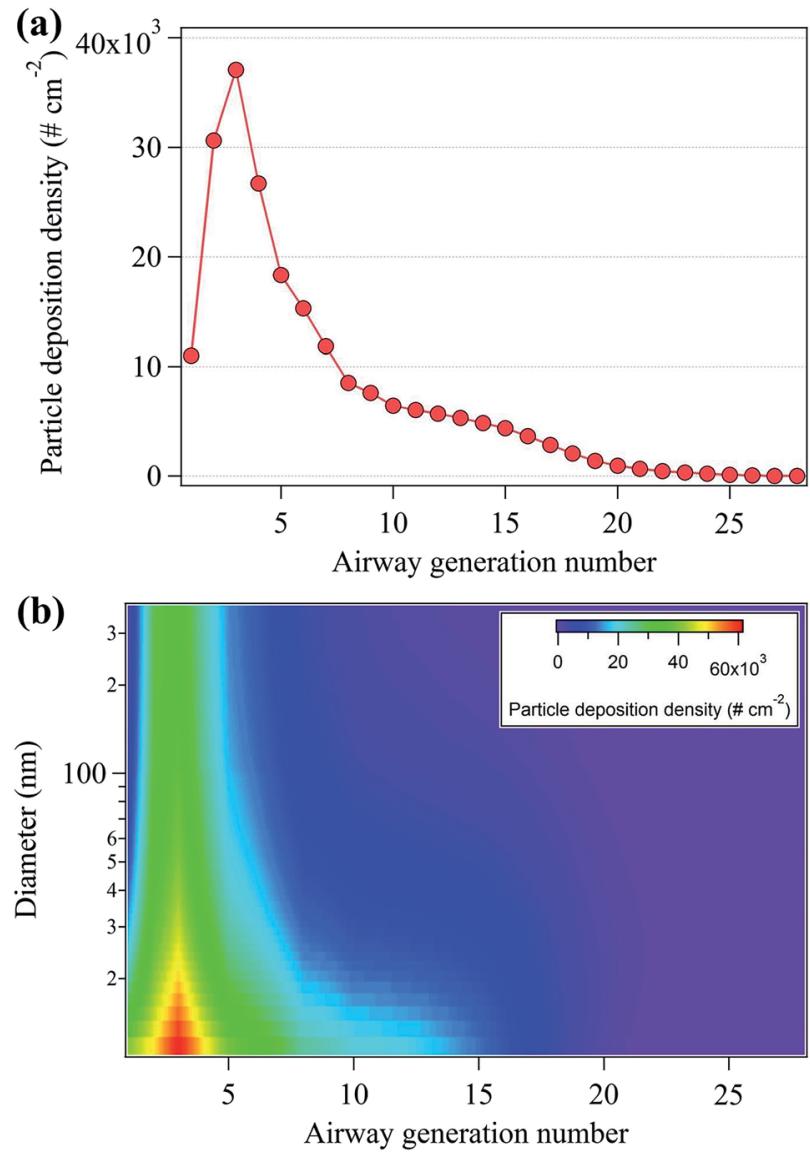

Fig. 6 (a) Total particle deposition density $\left(\# \mathrm{~cm}^{-2}\right)$ per human air generation number and (b) particle deposition density per human airway generation number and nanoparticle diameter.

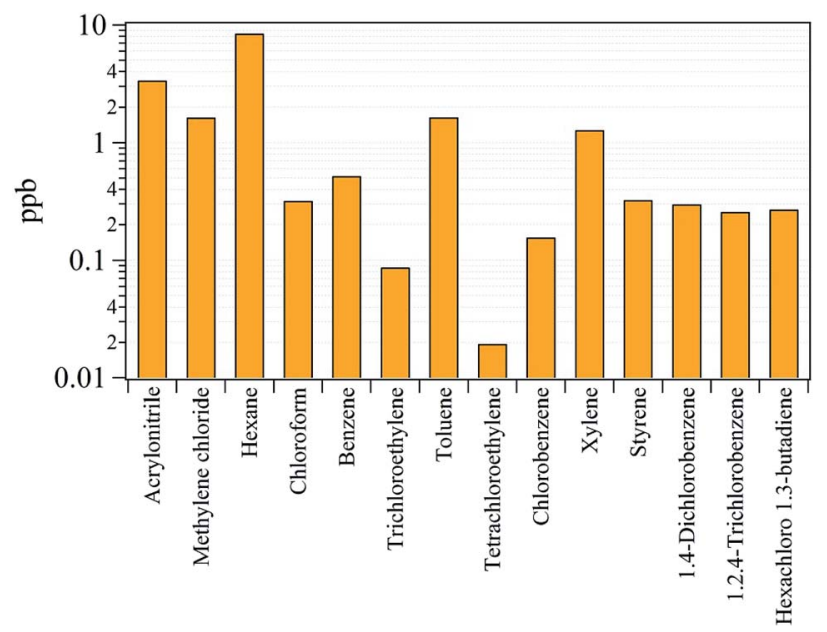

Fig. 7 Concentrations of the 14 species classified as hazardous air pollutants (HAPs).

cancer. ${ }^{47}$ Group $2 \mathrm{~A}$ and $2 \mathrm{~B}$ chemicals are defined as probably and possibly carcinogenic to humans. Of the HAPs classified as group $2 \mathrm{~A}$ and $2 \mathrm{~B}$, acrylonitrile, methylene chloride, chloroform, tetrachloroethylene, and styrene were detected at concentrations of $3.36,1.64,0.32,0.02$, and $0.33 \mathrm{ppb}$, respectively. The concentrations of hexane, toluene, xylene, and 1,2,4trichlorobenzene were $8.46,1.65,1.28$, and $0.26 \mathrm{ppb}$, respectively. These substances are not listed as carcinogens but are known to effects the central nervous system (CNS) after inhalation..$^{25}$ Chlorobenzene $(0.16 \mathrm{ppb}), 1,4$-dichlorobenzene $(0.30$ $\mathrm{ppb})$, and hexachloro-1,3-butadiene ( $0.27 \mathrm{ppb})$ are not classified as carcinogen or toxic to the CNS but are hazardous pollutants that can cause narcosis, irritation, and cardiac disease. ${ }^{25}$

\section{Conclusions}

This study assessed nanoparticle formation and the emission of HAPs from the operation of 3D printers. Nanoparticle deposition behavior in the human respiratory system was also studied. The main findings are as follows, in order of the research objectives presented at the end of Introduction: (1) nanoparticle emissions exhibited a bimodal size distribution, with dominant peaks at $10 \mathrm{~nm}$ and $88 \mathrm{~nm}$. Once the 3D printer was started, the generation of $10 \mathrm{~nm}$ size nanoparticles increased, and after a few minutes the concentration of $88 \mathrm{~nm}$ size nanoparticles increased; (2) most single nanoparticles were near spherical in shape, with a median primary particle size of $19.85 \mathrm{~nm}$. The single spherical nanoparticles agglomerated and existed in the form of larger particles; (3) 10-40 nm size nanoparticles were mostly deposited in the lower respiratory system with a generation number between 16 and 22, whereas particle deposition density was higher in the upper respiratory system due to a smaller surface area; and (4) 14 HAPs species generated by 3D printer operation were analyzed, indicating that they might cause cancer or other adverse health effects once they are inhaled into the human respiratory system. As an extension of this research, future studies should focus on the evaluation of nanoparticle emission using closed camber study and quantifying the doses of each HAPs species in the human respiratory tract to inform exposure assessments.

\section{Conflicts of interest}

There are no conflicts to declare.

\section{Acknowledgements}

This work was funded by the Korea Ministry of Environment (MOE) as "the Environmental Health Action Program (2016001360005) and funded by the Basic Science Research Program through the National Research Foundation of Korea (NRF) funded by the Ministry of Science and ICT (NRF2017R1C1B1008811).

\section{Notes and references}

$1 \mathrm{H}$. Lipson and K. Melba, Fabricated the new world of $3 D$ printing, 2013, vol. 53.

2 C. Schubert, M. C. Van Langeveld and L. A. Donoso, Br. J. Ophthalmol., 2014, 98, 159-161.

3 B. Berman, Bus. Horiz., 2012, 55, 155-162. 
4 F. Rengier, A. Mehndiratta, H. Von Tengg-Kobligk, C. M. Zechmann, R. Unterhinninghofen, H. U. Kauczor and F. L. Giesel, Int. J. Comput. Assist. Radiol. Surg., 2010, 5, 335-341.

5 R. Bogue, Assem. Autom., 2013, 33, 307-311.

6 E. Buehler, S. K. Kane and A. Hurst, in Proceedings of the 16th International ACM SIGACCESS Conference on Computers \& Accessibility, 2014, pp. 107-114.

7 J. W. Stansbury and M. J. Idacavage, Dent. Mater., 2016, 32, 54-64.

8 J. Skowyra, K. Pietrzak and M. A. Alhnan, Eur. J. Pharm. Sci., 2015, 68, 11-17.

9 D. Lithner, A. Larsson and G. Dave, Sci. Total Environ., 2011, 409, 3309-3324.

10 L. Mendes, A. Kangas, K. Kukko, B. Mølgaard, A. Säämänen, T. Kanerva, I. Flores Ituarte, M. Huhtiniemi, H. StockmannJuvala, J. Partanen, K. Hämeri, K. Eleftheriadis and A. K. Viitanen, J. Ind. Ecol., 2017, 21, S94-S106.

11 C. H. Shin, Y. Yoon, J. H. Park and B. C. Ma, Korean J. Chem. Eng., 2018, 35, 1225-1230.

12 J. Unwin, M. R. Coldwell, C. Keen and J. J. McAlinden, Ann. Occup. Hyg., 2013, 57, 399-406.

13 P. Azimi, D. Zhao, C. Pouzet, N. E. Crain and B. Stephens, Environ. Sci. Technol., 2016, 50, 1260-1268.

14 B. Stephens, P. Azimi, Z. El Orch and T. Ramos, Atmos. Environ., 2013, 79, 334-339.

15 N. Afshar-Mohajer, C. Y. Wu, T. Ladun, D. A. Rajon and Y. Huang, Build. Environ., 2015, 93, 293-301.

16 O. Kwon, C. Yoon, S. Ham, J. Park, J. Lee, D. Yoo and Y. Kim, Environ. Sci. Technol., 2017, 51, 10357-10368.

17 Y. Kim, C. Yoon, S. Ham, J. Park, S. Kim, O. Kwon and P. J. Tsai, Environ. Sci. Technol., 2015, 49, 12044-12053.

18 M. E. Vance, V. Pegues, S. Van Montfrans, W. Leng and L. C. Marr, Environ. Sci. Technol., 2017, 51, 9516-9523.

19 J. Heyder, J. Gebhart, G. Rudolf, C. F. Schiller and W. Stahlhofen, J. Aerosol Sci., 1986, 17, 811-825.

20 R. B. Schlesinger, Concepts in Inhalation Toxicology, 1989, 163-192.

21 S. S. Park and A. S. Wexler, J. Aerosol Sci., 2008, 39, 266-276.

22 C. Saraiva, C. Praça, R. Ferreira, T. Santos, L. Ferreira and L. Bernardino, J. Controlled Release, 2016, 235, 34-47.

23 K. Sexton, J. L. Adgate, G. Ramachandran, G. C. Pratt, S. J. Mongin, T. H. Stock and M. T. Morandi, Environ. Sci. Technol., 2004, 38, 423-430.

24 W. W. Nazaroff and B. C. Singer, J. Exposure Anal. Environ. Epidemiol., 2004, 14, S71-S77.

25 US EPA, Health Effects Notebook for Hazardous Air Pollutants, 2017, https:/www.epa.gov/haps/health-effects-notebookhazardous-air-pollutants, accessed 2019.
26 J. Yi, R. F. LeBouf, M. G. Duling, T. Nurkiewicz, B. T. Chen, D. Schwegler-Berry, M. A. Virji and A. B. Stefaniak, J. Toxicol. Environ. Health, Part A, 2016, 79, 453-465.

27 International Agency for Research on Cancer, Trichloroethylene, Tetrachloroethylene, and Some Other Chlorinated Agents, WHO, Geneva, 2014.

28 A. Voutilainen, J. P. Kaipio, J. Pekkanen, K. L. Timonen and J. Ruuskanen, Scand. J. Work, Environ. Health, 2004, 30, 7379.

29 M. Manigrasso, L. Stabile, P. Avino and G. Buonanno, Atmos. Environ., 2013, 67, 130-142.

30 H. C. Yeh, G. M. Schum and M. T. Duggan, Anat. Rec., 1979, 195, 483-492.

31 B. Asgharian, W. Hofmann and R. Bergmann, Aerosol Sci. Technol., 2001, 34, 332-339.

32 S. Anjilvel and B. Asgharian, Fundam. Appl. Toxicol., 1995, 28, 41-50.

33 National Institute for Public Health and the Environment (RIVM), Multiple Path Particle Dosimetry Model (MPPD v 1.0): A Model for Human and Rat Airway Particle Dosimetry, 2002.

34 J. Löndahl, A. Massling, E. Swietlicki, E. V. Bräuner, M. Ketzel, J. Pagels and S. Loft, Environ. Sci. Technol., 2009, 43, 4659-4664.

35 K. Oravisjärvi, M. Pietikäinen, J. Ruuskanen, A. Rautio, A. Voutilainen and R. L. Keiski, Sci. Total Environ., 2011, 409, 4511-4518.

36 Y. Zhang, W. Sumner and D. R. Chen, Nicotine Tob. Res., 2013, 15, 501-508.

37 S. Guha, P. Hariharan and M. R. Myers, Aerosol Sci. Technol., 2014, 48, 1226-1235.

38 A. E. Haddrell, J. F. Davies and J. P. Reid, Environ. Sci. Technol., 2015, 49, 14512-14521.

39 H. C. Yeh and G. M. Schum, Bull. Math. Biol., 1980, 42, 461480.

40 S. Froeschke, S. Kohler, A. P. Weber and G. Kasper, J. Aerosol Sci., 2003, 34, 275-287.

41 J. S. Youn, S. J. Park, H. Cho, Y. W. Jung and K. J. Jeon, Korean J. Chem. Eng., 2018, 9, 1948-1953.

42 W. C. Hinds, J. Aerosol Sci., 1999, 14, 175.

43 J. S. Youn, J. Csavina, K. P. Rine, T. Shingler, M. P. Taylor, A. E. Sáez, E. A. Betterton and A. Sorooshian, Environ. Sci. Technol., 2016, 50, 11706-11713.

44 H. Salem and S. A. Katz, Inhalation Toxicology, CRC Press, Boca Raton, 2014.

45 D. J. Paustenbach, J. Toxicol. Environ. Health, Part B, 2000, 3, 179-291.

46 International Agency for Research on Cancer, List of classifications by cancer site, 2015.

47 M. C. Rousseau, K. Straif and J. Siemiatycki, Environ. Health Perspect., 2005, 113, A580-A583. 